\title{
A Short Review on the Active Control Approaches in Earthquake Engineering at the Last 10 Years (2008-2018)
}

\author{
Arcan Yanik and Unal Aldemir
}

\begin{abstract}
This paper is written to present the state of the art of the new active and semi active approaches during the last decade. This is achieved by reviewing the active control approaches and semi-active control policies that have been proposed and validated analytically or numerically in the last ten years. All the papers reviewed in this study are within the scope of earthquake engineering. Brief information about these active control approaches and some of the resulting control policies are presented. To be able to show the effectiveness of the proposed approaches, the numerical examples of these papers are presented in this study. Because of the latest technological and computational advances, some of the most effective and complex algorithms have been studied and numerically validated during the last decade in earthquake engineering. This is the reason that this review considers the period of 2008-2018. The authors also include some of the new semi-active control policies that have been proposed numerically during the last decade. It has been concluded that, although there is an impressive research on numerically and/or analytically validating new active control approaches and new semi-active control policies of the years 2008-2018, there is not any real-building / real structure implementation of these active control approaches. Additionally there is a need of experimental validation of these active control methods that have been presented during the last decade.
\end{abstract}

Index Terms-Active control, earthquake engineering, semi-active control, structural engineering.

\section{INTRODUCTION}

The theoretical background for incorporating smart control devices into structures was first provided by Yao in 1972 [1]. He stated in his paper that control theories could be used in structural control problems, in other words in earthquake engineering area. Structural control can be categorized as passive, active, and hybrid control. The content of this paper is on active control. Active control methods are effective for a wide frequency range as well as for transient vibrations. Active control devices are always integrated with a power supply, real time controllers and sensors placed on the structure. While applying active control to structures with

Manuscript received August 6, 2018; revised December 23, 2018. This work was supported in part by the Istanbul Technical University Research Fund (No:41640).

A. Yanik was with Oregon State University, Corvallis, OR 97331, USA $\mathrm{He}$ is now with the Civil Engineering Department, Istanbul Technical University as an Asst. Prof. Dr., Maslak, Istanbul 34469 Turkey (phone: +90 212-285-3708; +90 212-285 6587, e-mail: yanikar@itu.edu.tr).

U. Aldemir (Prof. Dr.) is the Dean of Istanbul Technical University, Civil Engineering Faculty, Maslak, Istanbul 34469 Turkey (phone: +90 212-285-3855; fax: +90 212-285-3855; e-mail: aldemiru@itu.edu.tr). active tendon controllers, or other active control devices, an appropriate active control algorithm must be selected. Presently active control of earthquake engineering structures is a very interesting area of research. Because there are still lots of challenges that need to be solved analytically/theoretically. Some of these challenges are computational time delays, balancing displacement and absolute accelerations of the structures and possible power outages during earthquakes and optimization problems. To overcome these problems, researchers began studying semi-active control methods. Semi-active control systems are a class of control systems in which the control actions are applied by changing the mechanical properties (i.e., stiffness and damping) of the control device. The advantages of using these control systems are presented below.

The external energy requirements of the semi-active control devices are smaller than typical active control systems. Semi-active control devices can only absorb or store vibration energy in the structure by reacting to its motion. They seem to combine the best futures of passive and active systems. Magneto-rheological dampers, electrorheological dampers (MR and ER dampers), controllable friction devices and controllable viscoelastic dampers are some of the most important examples of semi-active dampers.

In the literature the authors did not find any study on the review of the new active control and semi active control approaches presented during the last ten years. The latest state of the art of the new active and/or semi active control approaches was not found in the literature. Therefore this study is on the review of new active control approaches that have been presented in the last decade. In addition to this some of the newly presented semi-active control policies are also included in this paper. The review is given in two sections. The next (Section II) is on the review of proposed new active control approaches in the last decade and Section III is on the review of proposed semi-active control policies during the last decade. The studies are explained in chronological order in Section II and III. After the literature review on new active control approaches and semi-active control policies, the authors found just a single study on experimental validation of a newly proposed active control approach.By newly proposed active control approaches the authors refer to the approaches that have been proposed during the last decade. They don't address some of the active control approaches that had been experimentally validated before the year 2008. It should also be stated here that some active control approaches that had been developed before 2008 has already been implemented in real life applications. Taipei building in Taiwan, Senteyaga Intes and Yokohama 
Landmark tower buildings in Japan can be shown as some examples of real life active control applications [2]. However all of the new active control approaches except one of them were validated numerically or analytically during the last decade, therefore in Section II and III, the examples of the analytical or numerical models of some of these studies are presented. The reason for including some of the figures is to show the simplicity and similarity of the numerical models of these studies. In addition to the figures, the resulting control approaches (active or semi-active control forces, control laws, input voltage equations etc.) derived from these studies are presented in their simplest form. It should be stated here that, there are numerous interesting studies on active control of earthquake engineering structures that have been carried out during the last decade but this review paper only considers the new active / semi-active control approaches that have been presented in the last ten years.

\section{NeW ACtive CONTROL APPROACHES PRESENTED DURING THE LAST DECADE FOR EARTHQUAKE ENGINEERING}

The first study is on an active control approach based on $\mathrm{H}_{2}$ and $H_{\infty}$ control [3]. Mixed $H_{2} / H_{\infty}$ control strategies were formulated by means of linear matrix inequality (LMI) to attenuate the transient vibration of the flexible rotor system under a non-stationary seismic excitation and to improve robust performance of the flexible rotor system. The double-disc cantilever flexible rotor example is shown in Fig. 1 [3]. The optimal feedback control law of their control system was given as

$$
\mathbf{u}=\mathbf{W} \mathbf{X}^{-1} \mathbf{x}
$$

where $\mathbf{x}$ is the state vector, $\mathbf{X}$ is the symmetric positive semi-definite matrix obtained by solving the Lyapunov equation and $\mathrm{w}$ is the exogenous input.

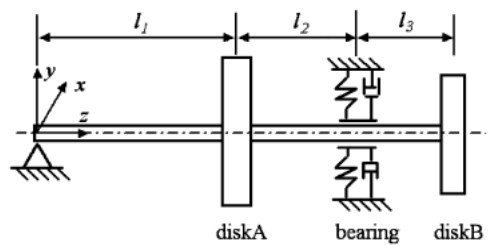

Fig. 1. Double disc cantilever rotor example. Fig. 1 taken from [3].

For active control of a large structure a bilinear pole-shifting technique with $H \infty$ control method was proposed for the dynamic response control in [4]. Their proposed control method is a direct pole-placing design approach. This can make the structural systems have a certain target damping ratio. They used two simple numerical examples to validate their control algorithm. One of their examples is a single degree of freedom (SDOF) system which is given in Fig. 2. And the other example is again a simple ten story shear frame structure [4]. As seismic excitations they used El Centro, Northridge, Hachinohe, and Kobe earthquakes, which have different frequency contents and peak values. In Fig. 2 and in most of the figures that are presented in this paper $m, c$ and $k$ represent the mass, damping and stiffness of the corresponding system. $x(t)$ represent time dependent displacement of the structure, $\ddot{x}_{g}(t)$ stands for earthquake ground acceleration. $u_{f}(t)$ or $u(t)$ stands for the time dependent displacement of each story.

A new simple non-linear control model for active control of three-dimensional (3D) high-rise building structures was presented in [5]. A neuro-genetic algorithm or controller was presented for finding the optimal control forces in [6]. References [5] and [6] are companion papers that use the same numerical simple 3D example model given in Fig. 3.

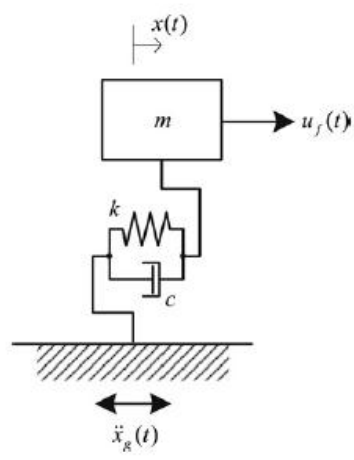

Fig. 2. SDOF system excited by ground acceleration. Fig. 2 taken from [4].

Their optimal control problem was formulated as a constrained non-linear optimization problem as follows.

$$
\begin{aligned}
& \text { ff } \left.\mathbf{F}_{j}\right)=\bar{d}_{j}-\min \left\{\bar{d}_{R}, d_{\max }\right\}=\frac{\sum_{i=0}^{p} \sqrt{\left[\hat{x}^{i}\left(\mathbf{F}_{j}\right)\right]^{2}+\left[y^{i}\left(\mathbf{F}_{j}\right)\right]^{2}}}{p+1} \\
& -\min \left\{\bar{d}_{R}, d_{\text {max }}\right\}
\end{aligned}
$$

where $d_{j}$ is the displacement at the $i$ th prediction (future) time step of the control loop in the $j$ th time step of the earthquake $x^{i}(\mathbf{F} j)$ and $y^{i}(\mathbf{F} j)$ are the predicted structural displacements along two convenient $x$ - and $y$-axes, respectively, obtained using the $x$ - and $y$-neuroemulators and $p$ is the number of future time steps described in [5]

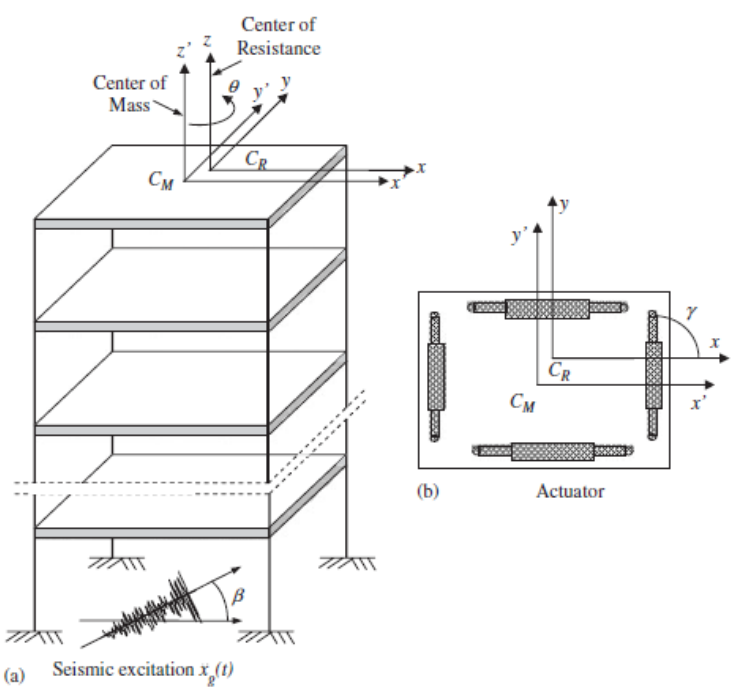

Fig. 3. Simple structural model of a 3D building: (a) 3D building and (b) typical story with four actuators taken from [5]. 
A simple evaluation of the disturbance weighting parameter of well-known minimax disturbance attenuation problems derived for earthquake-excited structures was presented in [7]. He stated in his paper that for a system under optimal minimax control, the system matrix $\mathbf{A}$ of the uncontrolled structure is replaced by the following parameter

$$
\left[\mathbf{A}^{-}\left(\mathbf{B} \mathbf{R}^{-1} \mathbf{B}^{\mathrm{T}}-(1 / . q) \mathbf{H} \mathbf{H}^{T}\right) \mathbf{P}_{n s}\right]
$$

where $\mathbf{B}$ is the sytem matrix , $\mathbf{R}$ is the symmetric positive semi-definite weighting matrix and $\mathbf{P}_{n s}$ is the solution of non-standard Riccati equation [7].

A simple active control algorithm for earthquake excited structures was proposed in [8]. The resulting control policy (active control force) is given in (4). In (4) $\mathbf{Q}$ is the positive semidefinite symmetric weighting matrix, $\mathbf{R}$ is the ( $r \times$ $r$ )-dimensional positive definite symmetric weighting matrix (where $\mathrm{r}$ is the number of controllers); $h$ is the time interval between the successive control instants $\mathbf{Z}$ is the state vector and $\mathbf{N}_{0}$ is the gain matrix. The numerical examples in [7] and [8] are both 2 degree of freedom shear buildings.

$$
\mathbf{U}(t)=-h \mathbf{N}_{0}^{-1} \mathbf{R}^{-1} \mathbf{B}^{\mathrm{T}} \mathbf{Q} \mathbf{Z}(t)
$$

Linear Matrix Inequality (LMI) based state-feedback mixed $\mathrm{H} 2 / \mathrm{H} \infty$ controller was designed in [9]. Their study was concerned with the active vibration control of a four-degree-of-freedom simple model structure, which is effected by earthquake as given in Fig. 4.

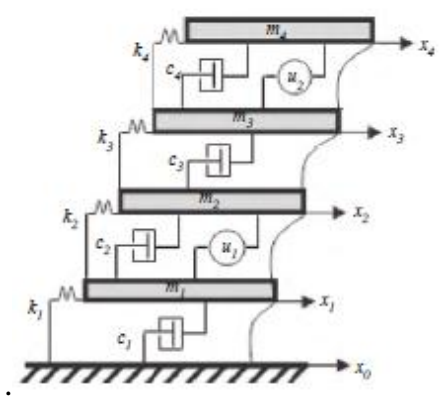

Fig. 4. Numerical model of a four degree of freedom structure system taken from [9].

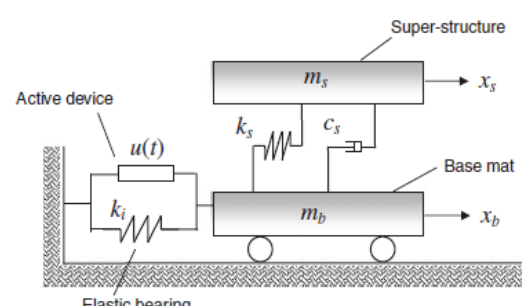

Elastic bearing

Fig. 5. Mathematical model of the active isolation system. taken from [10].

To improve the performance of active isolation systems (AISs) for acceleration sensitive equipment or structures, two optimal control laws that utilize performance indices associated with system absolute energy were proposed in [10]. The first control law, which requires the measurement of the ground velocity in deciding the control force, is derived based on the concept of instantaneous optimal control. The second one is based on the concept of discrete-time optimal control, in which the feedback gain can be obtained by solving the discrete-time algebraic Riccati equation. The simple mathematical model of the active isolation system studied in [10] shown in Fig. 5. The three control law that have been defined in their study is shown in Table I. In Table I $\mathbf{z}_{\mathrm{a}}[\mathrm{k}]$, $\mathbf{z}_{\mathrm{a}}(\mathrm{k}+1), \mathbf{z}_{\mathrm{r}}[\mathrm{k}], \mathbf{z}_{\mathrm{r}}(\mathrm{k}+1)$ are the state vectors at the $\mathrm{k}$-th and $\mathrm{k}+1$ -th time steps, $R$ is a weighting factor for the control force $u[\mathrm{k}]$ and $\mathbf{G}$ is the control gain

TABLE I: CONTROL LAWS DEFINED IN [9]

\begin{tabular}{|c|c|c|}
\hline Control law & Performance index & Control force \\
\hline $\begin{array}{c}J_{\mathrm{a}, \mathrm{gv}} \text { (Absolut } \\
\text { e energy) }\end{array}$ & $\mathbf{z}_{\mathrm{a}}{ }^{\mathrm{T}}[k+1] \mathbf{Q} \mathbf{z}_{\mathrm{a}}[k+1]+R u^{2}[k]$ & $u[k]=\mathbf{G} \mathbf{z}_{\mathrm{a}}[\mathrm{k}]+G_{\mathbf{g}} \dot{x}_{g}[$ \\
\hline $\begin{array}{c}J_{\mathrm{a}} \text { (Absolute } \\
\text { energy) }\end{array}$ & $\sum_{k=0}^{m}\left(\mathbf{z}_{a}^{T}[k] \mathbf{Q} \mathbf{z}_{a}[k]+R u^{2}[k \|)\right.$ & $u[k]=\mathbf{G z}_{\mathrm{a}}[\mathrm{k}]$ \\
\hline $\begin{array}{c}J_{\mathrm{r}} \text { (Relative } \\
\text { energy) }\end{array}$ & $\sum_{k=0}^{m}\left(\mathbf{z}_{r}{ }^{T}[k] \mathbf{Q} \mathbf{z}_{r}[k]+R u^{2}[k]\right)$ & $u[k]=\mathbf{G z}_{\mathrm{r}}[\mathrm{k}]$ \\
\hline
\end{tabular}

A minmax optimization method for the active vibration control system considering uncertain dynamics was presented in [11]. Example design of an earthquake-excited building structure with active tendon control system was performed and comparative results of numerical simulation were presented to validate their proposed method. As numerical example they used a nine-story shear building structure with active tendon control system shown in Fig. 6 [11].

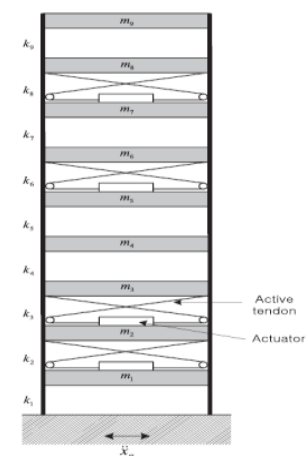

Fig. 6. Shear building structure with active tendon control system [11].

An active vibration control technique to reduce the seismic response of a soil-retaining structure interaction (SRSI) system was presented in [12]. Their proposed control technique is a synthesis of the adaptive input estimation method (AIEM) and the linear quadratic Gaussian (LQG) controller. The dynamic 2 degree of freedom model of their study is shown in Fig 7 [12].
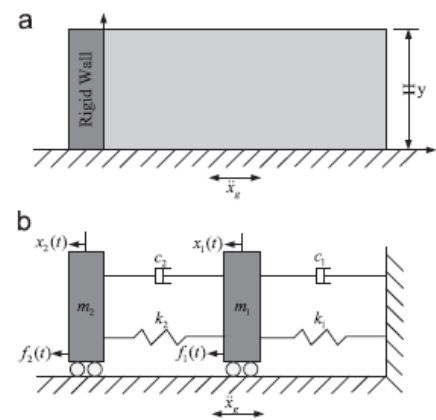

Fig. 7. 2-DOF dynamic model taken from [12]. 
A new performance index for active control of structures under earthquake excitation was proposed in [13]. Their resulting closed-loop control algorithm does not need the future knowledge of earthquake and also does not require the solution of the nonlinear matrix Riccati equation. They investigated the performance of the proposed control numerically by using two shear frame structures (10 story and 3 story), subjected to various seismic inputs [13]. The optimal active control force was given with (2) where $\mathbf{G}_{\mathrm{pc}}$ is the gain matrix, more information on this equation can be found in [13].

$$
\mathbf{U}(t)=-\mathbf{G}_{p c} \mathbf{Z}(t)
$$

A nonlinearly parameterized controller for the adaptive control of base-isolated buildings subjected to a set of nearfault earthquakes was presented in [14]. Their control scheme is based on discrete direct adaptive control, wherein the system response is minimized under parameter uncertainties. The numerical finite element is given in Fig. 8 [14]. The control force from their study is given as

$$
F_{c}^{*}(k)=\Im\left(y(k-1), \ldots, y(k-n), \ddot{U}_{g}(k), \ldots, \ddot{U}_{g}(k-n)\right.
$$

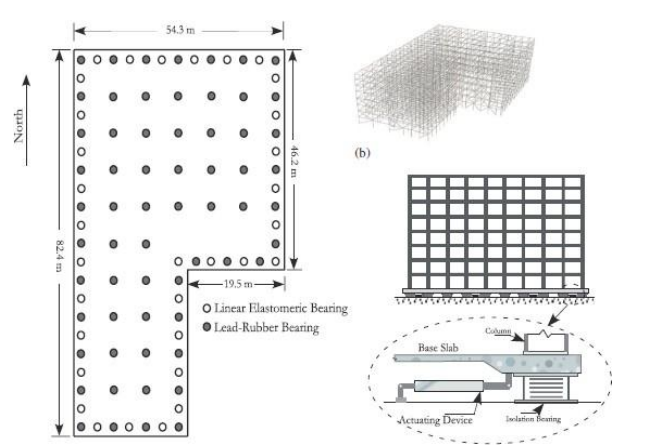

Fig. 8. Finite element model of the eight-story base-isolated building and actuator placement detail [14].

In (6) $k$ is the current and $n$ is the past values of the response measurements, and $y$ is the response $\mathfrak{I}$ is a nonlinear function and $\ddot{U}_{g}$ is the ground acceleration vector. A decentralized control algorithm was proposed for large- scale linear building structures in [15]. In their study a large- scale building structure shown in Fig. 9 was divided into a set of smaller substructures based on its finite element model. The optimal control force derived from their study is presented in (7). In (7) $\tilde{\boldsymbol{Z}}_{r}[k+1]$ is the estimated state vector and $\boldsymbol{G}_{\mathrm{rd}}$ is the gain matrix. A wavelet- based fuzzy neuro control algorithm for the hazard mitigation of seismically excited buildings equipped with a hybrid control system was proposed in [16]. For numerical validation of their algorithm they used simple eight story shear frame structures. A new performance index for active vibration control of three-dimensional structures was presented in [17]. To analytically validate the proposed performance index, a six story three-dimensional structure was considered as an example with a fully active tendon controller system. This example is shown in Fig. 10 and the resulting control law from their study is given in (8) [17].

In (8) $\mathbf{Z}_{3 D}$ is the three dimensional state vector, $\Delta t$ is the sampling interval of the simulation and the other parameters are defined above. A controller for the seismic-excited buildings with active fault tolerant control was designed in [18]. They stated that in comparison with the existing works that have already been reported in the literature their control desing approach shows better performance. Their numerical example is shown in Fig. 11.

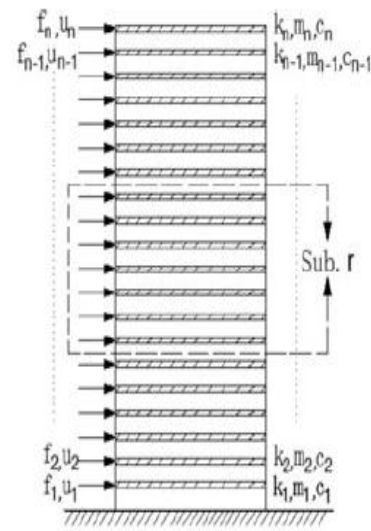

(a)

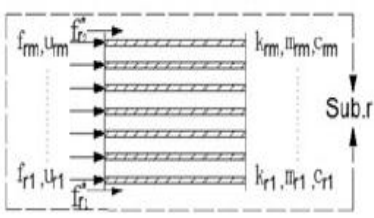

(b)
Fig. 9. Large scale building model [15].

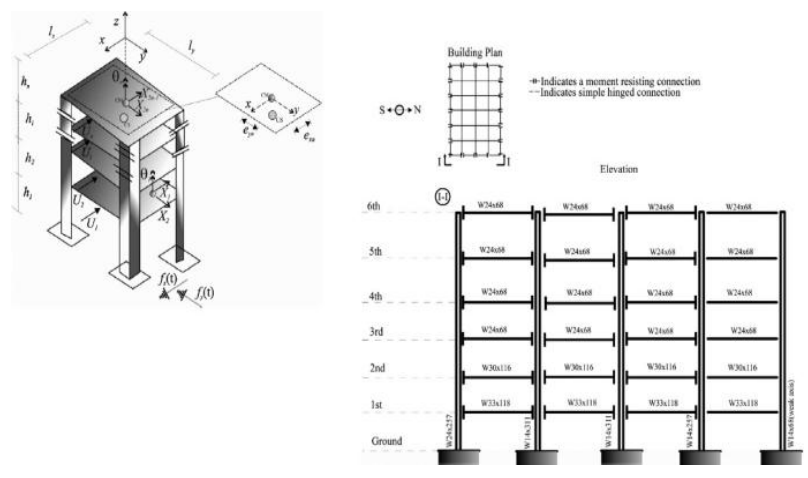

Fig. 10. 3D tier building scheme with $2 \mathrm{D}$ plan of the numerical example [17].

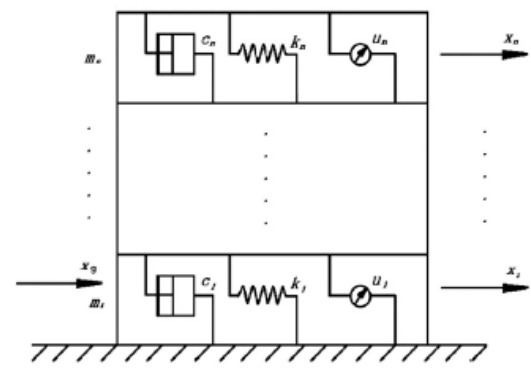

Fig. 11. The building system taken from [18].

$$
\begin{gathered}
\boldsymbol{U}_{r}[k+1]=-\boldsymbol{G}_{r d} \tilde{\boldsymbol{Z}}_{r}[k+1] \\
\mathbf{U}(t)=-\left[2 \mathbf{R}+\frac{\Delta t}{2} \mathbf{B}^{\mathrm{T}} \mathbf{H}_{1}\right]^{-1}\left[\Delta t \mathbf{B}^{\mathrm{T}} \mathbf{Q}+\mathbf{H}_{1}^{\mathrm{T}}\right] \mathbf{Z}_{3 D}(t)
\end{gathered}
$$

A wavelet-filtered genetic-neuro-fuzzy (WGNF) control system design framework for response control of a highway bridge under various earthquake loads was discussed in [19]. The WGNF controller was developed by combining fuzzy logic, discrete wavelet transform, genetic algorithms, and neural networks for use as a control algorithm. They used a benchmark bridge (bridge deck) for numerical validation of their control algorithm as shown in Fig. 12. A closed loop 
control approach for controlling the vibration of buildings under earthquake excitations was presented in [20]. Active vibration control for seismic excited building structures in presenting of actuator saturation, stochastic measurement noise and quantization was proposed in [21] (see Fig. 13). The active vibration controllers are placed in some storeys, meanwhile, some active tuned mass dampers (ATMDs) are also installed at the top floor and oscillating under their control forces [21]. A fuzzy logic-based control algorithm was developed to control a nonlinear high-rise structure under earthquake excitation using active mass damper device was proposed in [22]. They used a 20-story benchmark nonlinear structure for the numerical studies that is given in Fig. 14. In their fuzzy logic based control state feedback $K$ is obtained with the well known quadratic cost function $J$ and with the help of (9) as given below for a two story structure.

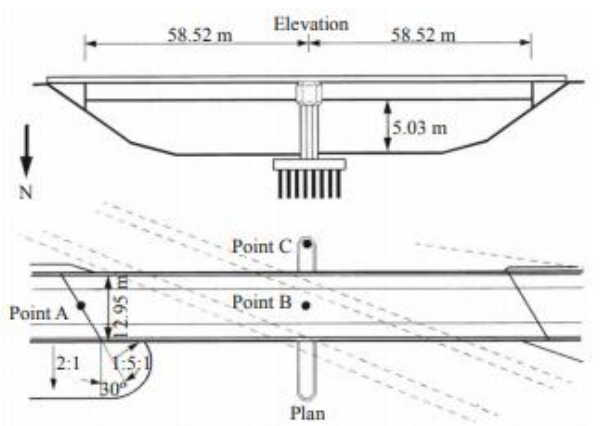

Fig. 12. Bridge deck example of [19].

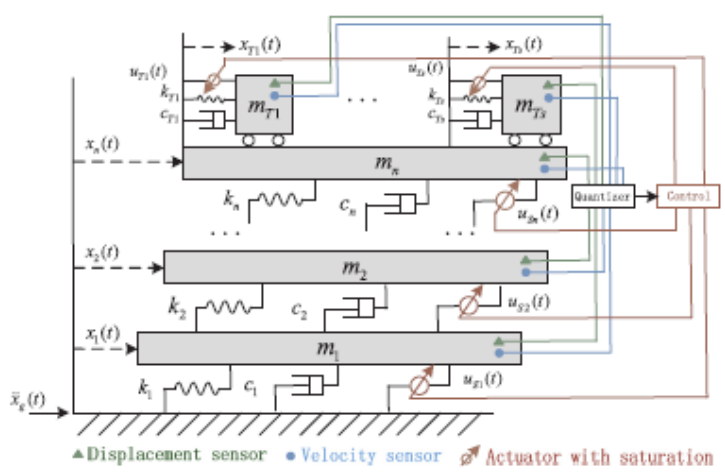

Fig. 13. Overall control structure of [21].

$$
\begin{aligned}
& X=\left(k_{1}, k_{2}, k_{3}\right)\left(\begin{array}{c}
x_{1} \\
x_{2} \\
x_{3}
\end{array}\right) \quad, \quad V=\left(k_{4}, k_{5}, k_{6}\right)\left(\begin{array}{c}
\dot{x}_{1} \\
\dot{x}_{2} \\
\dot{x}_{3}
\end{array}\right) \\
& \left(k_{1}, k_{2}, k_{3}, k_{4}, k_{5}, k_{6}\right)=K /\|K\|
\end{aligned}
$$

In (9) $x_{1}, x_{2}, \dot{x}_{1}, \dot{x}_{1}$ are the displacement and velocity of the structure, respectively. $x_{3}$ and $x_{3}$ are the displacement and velocity of the active mass damper control system.

A new robust control system was proposed for control of an hybrid active tuned mass damper (AMD) in a high-rise building in [23]. Their proposed controller was implemented in the test structure and its performance under seismic disturbances was simulated using a seismic shake table [23]. The next section is on the newly proposed semi-active control policies in the last decade.

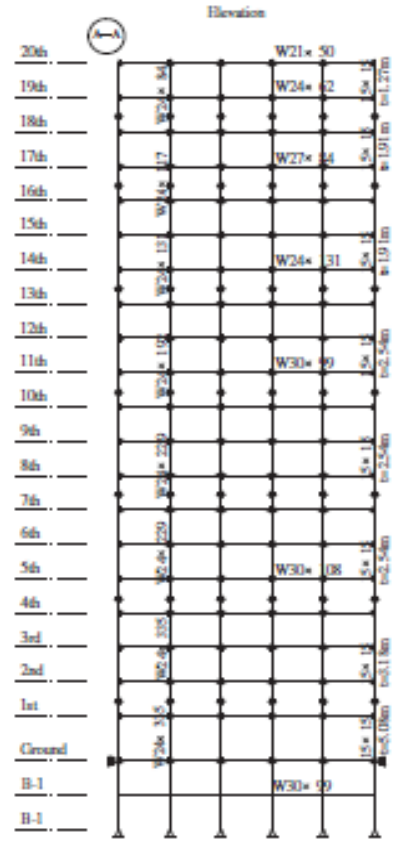

Fig. 14. Twenty-story benchmark building. [22]

\section{NEW SEMI-ACTIVE CONTROL APPROACHES PRESENTED DURING THE LAST DECADE}

The first study reviewed in this section is on an implementable proposed predictive control algorithm for suppressing the earthquake response using a nonlinear semi-active damper [24]. The performance of a simple 2-DOF base-isolated structure was investigated numerically and given in Fig. 15 [24].

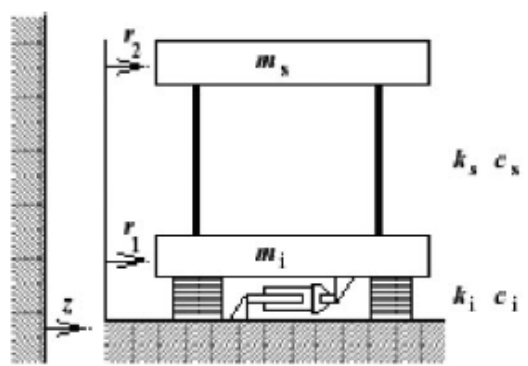

Fig. 15. Idealized model for a 2-degree-of-freedom base-isolated structure [24]

The proposed cost function is given as

$$
J=\int_{t_{0}}^{t_{f}} L(x(t), u(t), t) d t=\int_{t_{0}}^{t_{f}}\left[\ddot{r}_{2}(t)+\ddot{z}(t)\right]^{2} d t
$$

where the Lagrangian $L(\mathbf{x}(t), u(t), t)$ is the square of the superstructure absolute acceleration. Two semi-active control methods for seismic protection of structures using MR dampers were presented in [25]. They used a simple shear frame structure incorporating two MR dampers for numerical simulations under two far field and two near field earthquakes. This shear frame example is presented in Fig. 16. Development of a semi-active control algorithm based on several performance levels anticipated from an isolated building during different levels of ground shaking corresponding to various earthquake hazard levels was given in [26]. Their proposed performance-based algorithm was 
based on a modified version of the well-known semi-active skyhook control algorithm which is written below. In (11) $F_{s a}$ is the modified no-jerk skyhook control algorithm. $C_{s k y}$ is the skyhook gain, $V_{a b s}$ is the absolute velocity of the isolated mass and $V_{r e l}$ is the relative velocity across the damper.

$$
F_{s a}=\left\{\begin{array}{cc}
-C_{s k y} \cdot V_{a b s} \cdot\left|V_{r e l}\right| & V_{a b s} \cdot V_{r e l} \geq 0 \\
0 & V_{a b s} \cdot V_{r e l}<0
\end{array}\right.
$$

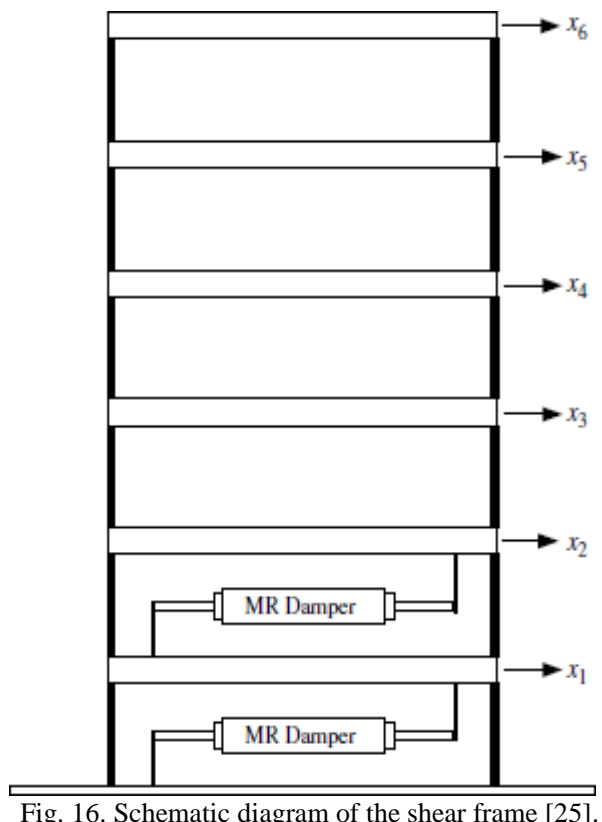

A fuzzy rule-based semi-active control of building frames using semi-active hydraulic dampers (SHDs) was presented in [27]. Their control approach was validated by using 3-story and 10 story shear frame structures under El Centro earthquake [27]. They adopted the center-of-gravity (COG) method among the defuzzification methods. For the $j$-th rule of the $i$-th damper, their COG method is presented in (12). In (12) $N_{R}$ is the number of rules applied to the given input, $\mu_{i}^{j}$ is the output membership function corresponding to the fuzzy variable defined in the consequent statement of the $j$ th rule for the $i$ th input, $b_{i}^{j}$ is the center of the output membership function $\mu_{i}^{j}$, and $\int \mu_{i}^{(j)}$ represents the area of the output membership function $\mu_{i}^{j}$.

$$
y_{i}=\frac{\sum_{j=1}^{N_{R}} b_{i}^{(j)} \int \mu_{i}^{(j)}}{\sum_{j=1}^{N_{R}} \int \mu_{i}^{(j)}}
$$

A direct semi-active control method is introduced to mitigate the seismic responses of structures equipped with magneto-rheological (MR) dampers was presented in [28]. Their algorithm was applied to control seismic vibrations of a three-story and an 11-story sample shear building that have been equipped with the MR damper control system. The optimal proposed voltage applied to each damper in each time step is given in (13). In (13) $\Delta t$ is a small time interval, $\mathrm{v}$ is the applied voltage, $\mathrm{u}$ is the efficient voltage, $\mathrm{r}$ is the number of dampers. $V_{\max }$ denotes the maximum voltage that is associated with the saturation of magnetic field in the MR damper.

$$
v_{k}=\left\{\begin{array}{cc}
0 & v_{k} \leq 0 \\
\mathrm{u}_{k}-\mathrm{u}_{0 k} e^{-\eta \Delta t} & 0 \leq v_{k} \leq V_{\max } \quad, \quad \mathrm{k}=1 \sim \mathrm{r} \\
V_{\max }^{1-e^{-\eta \nu t}} & V_{\max } \leq v_{k}
\end{array}\right.
$$

A 3-DOF per floor tier building analytical model which can incorporate models of either traditional tuned mass dampers (TMD) or MR dampers (MR-MD) was presented in [29]. Their 2D building plan is converted to a 3DOF tier building and given in Fig. 17. They stated that a desired damper force can be calculated from the present values of the state vector and mod-el parameters estimated off-line as given in (14). In (14) $i$ is the input current, $\ddot{x}$ and $\dot{x}$ are the acceleration and velocity of the MR damper respectively. $M$, $N$ and the coefficients in $f(i)$ and $g(i)$ ) can be determined from force-velocity data at several input current levels by a prediction error method, in a minimum mean-square error sense

$$
\begin{aligned}
& \ddot{x}>0 \\
& F_{d}^{+}(\dot{x}, i)=\frac{f(i)}{\pi}\left[\arctan \left(M\left(\dot{x}-\dot{x}_{0}\right)\right)+N\left(\dot{x}-\dot{x}_{0}\right)\right]+g(i), \\
& \ddot{x}<0 \\
& F_{d}^{+}(\dot{x}, i)=\frac{f(i)}{\pi}\left[\arctan \left(M\left(\dot{x}+\dot{x}_{0}\right)\right)+N\left(\dot{x}+\dot{x}_{0}\right)\right]-g(i),
\end{aligned}
$$

A wavelet neural network-based semi-active control model was proposed in order to provide accurately computed input voltage to the magneto-rheological dampers to generate the optimum control force of structures in [30]. Their model was optimized by a localized genetic algorithm and then applied to a nine-story benchmark structure subjected to $1.5 \times$ El Centro earthquake. They performed the dynamic analysis in one direction (north-south) and used the benchmark structure numerical model for their validations. Their numerical example model is shown in Fig. 18 [30].

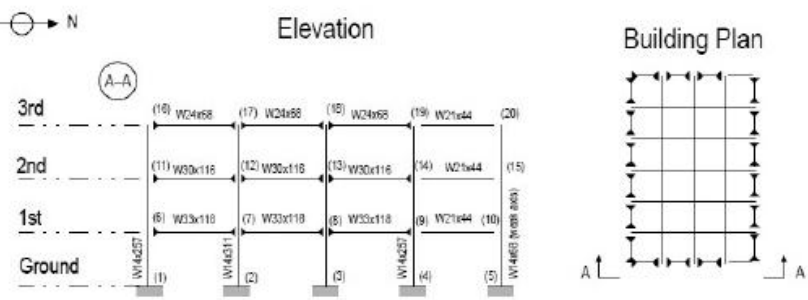

Fig. 17. 2D building plan and elevation [29]

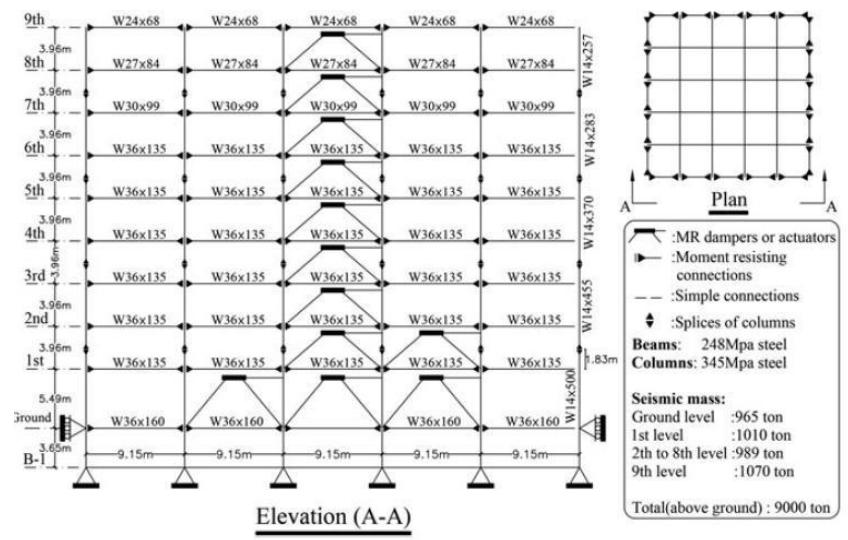

Fig. 18. Nine-story benchmark building [30]. 
A semi-active control strategy, in which $\mathrm{H} \infty$ control algorithm was used and magneto-rheological dampers were employed for an actuator, was presented to suppress the nonlinear vibration in [31]. Their numerical example was a twenty story benchmark building (Fig. 19). The proposed semiactive control strategy was expressed as below. In (15) $f_{\text {semi }(i)}$ denotes the actuator force generated by the $i$-th MR damper; $\hat{f}_{i}$ is the $i$-th element of $\hat{f} . F_{\min }$ and $F_{\max }$ are the minimum and maximum damping forces of all magneto-rheological dampers. The control law described represents a semi-active $\mathrm{H} \infty$ control strategy.

$$
\begin{aligned}
& f_{\text {semi }(i)=\alpha_{i} \cdot \hat{f}_{\text {semi }(i)}} \\
& =\alpha_{i}\left\{\begin{array}{l}
\frac{1}{\alpha_{i}} F_{\max } \quad \text { if } \hat{f}_{i} \cdot f_{\text {semi }(i)}>0 \text { and }\left|\hat{f}_{i}\right| \geq \frac{1}{\alpha_{i}} F_{\max } \\
\hat{f} \quad \text { if } \hat{f}_{i} \cdot f_{\text {semi }(i)}>0 \text { and }\left|\hat{f}_{i}\right|<\frac{1}{\alpha_{i}} F_{\max } \quad i=1, ., \mathrm{r} \\
\frac{1}{\alpha_{i}} F_{\min } \\
\text { if } \hat{f}_{i}, f_{\text {semi }(i)} \leq 0
\end{array}\right.
\end{aligned}
$$

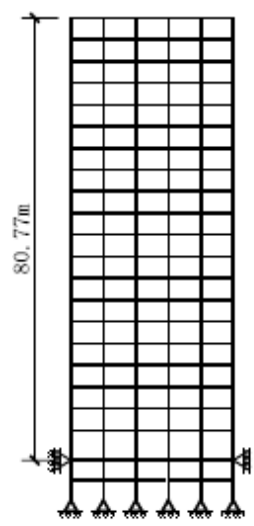

a

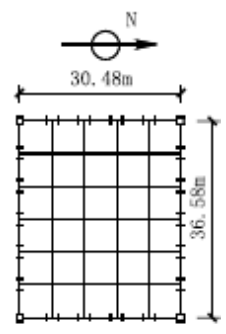

b
Fig. 19. Twenty-story benchmark building [31].

The application of a semi-active fuzzy based control system for seismic response reduction of a single degree-offreedom (SDOF) framed structure using a Magnetorheological (MR) damper was presented in [32]. They mentioned that the results of the numerical simulations showed the effectiveness of the suggested semi-active control system in reducing the response of the SDOF structure.

\section{CONCLUSION}

After the review on new active control and semi- active control algorithms that have been proposed in the last decade, it was observed that there are no applications or implementation of these control algorithms in real life earthquake engineering structures. As it can be understood from this paper, all the studies except one of them were numerical or analytical. The authors should mention here that there are some successful implementations of active control devices to real buildings, few of these examples are Taipei building in Taiwan, Senteyaga Intes and Yokohama Landmark towers in Japan. However the studies that were reviewed in this papers correspond to the last decade and there is no real-building or real structure implementation of them was found. Besides the lack of real life implementation of these approaches, there is a big need of experimental studies on validation of these new active and semi-active control approaches. For future studies the experimental research on the active and semi-active control approaches that were proposed during the last decade can be very interesting and valuable. The authors of this study are hoping to work on the validation of some of these active or semi-active control algorithms at the Istanbul Technical University, Faculty of Civil Engineering, Vibration Control and Research and Development lab.

\section{ACKNOWLEDGMENT}

The authors gratefully acknowledge the support from Istanbul Technical University Research Fund (No:41640). Any opinions and conclusions are those of the authors and do not necessarily reflect the views of the supporter.

\section{REFERENCES}

[1] J. T. P. Yao, "Concept of structural control," Journal of Structural Division ASCE, vol. 98, pp. 1567-1574, 1972.

[2] T. T. Soong and B. F. Spencer, "Supplemental energy dissipation: state-of-the-art and state-of-the-practice," Engineering Structures, vol. 24, 2002, pp. 243-259.

[3] Y. Chen and C. Zhu, "Active vibration control based on linear matrix inequality for rotor system under seismic excitation," J. Sound Vib, vol. 314, no. 1, pp.53-69, July 2008.

[4] W. Park, K. S. Park, and H.M. Koh, "Active control of large structures using a bilinear pole-shifting transform with $\mathrm{H} \infty$ control method," Eng Struct, vol.30, no.11, pp. 3336-3344, Nov. 2008.

[5] X. Jiang and H. Adeli, "Dynamic fuzzy wavelet neuroemulatorfor nonlinear control of irregular high risebuilding structures," Int J Numer Meth Eng, vol. 74, no. 7, pp. 1045-1066, May 2008.

[6] X. Jiang and H. Adeli, "Neuro-genetic algorithm for nonlinear active control of highrise buildings," Int J Numer Meth Eng, vol.75, no. 8, pp.770-786, Aug. 2008.

[7] U. Aldemir, "Evaluation of disturbance weighting parameter of minimax attenuation problems," Comput-Aided Civ Inf, vol. 24, no. 4, pp.302-308, May 2009.

[8] U. Aldemir, "A simple active control algorithm forearthquake excited structures," Comput-Aided Civ Inf, vol. 25, no. 3, pp. 218-225, 2010.

[9] H. Yazici and R. H. Guclu, "Active vibration control of seismic excited structural system using LMI-based mixed H_2/H_ \{linfty\} state feedback controller," Turk J Electr Eng Co, vol. 19, no. 6, pp. 839-849, 2011.

[10] L.Y. Lu, G. L. Lin, and C. C. Lin, "Absolute-energy-based active control strategies for linearseismic isolation systems," Struct Control Health, vol.18, pp. 321-340, Apr. 2011.

[11] K. S. Park and W. Park, "Minmax optimum design of active control system for earthquake excited structures," Adv Eng Softw, vol. 51, pp. 40-48, Sept. 2012.

[12] M. H. Lee, "Active control to reduce the horizontal seismic response of buildings taking into account the soil-structure interaction," Soil. Dyn. Earthq. Eng., vol. 42, pp. 132-136, July 2012.

[13] U. Aldemir, A. Yanik, and M. Bakioglu, "Control of structural response under earthquake excitation," Comput-Aided Civ Infrastruct, vol. 27, no. 8, pp. 620-638, Sept. 2012.

[14] S. Suresh, S. Narasimhan, and S. Nagarajaiah, "Direct adaptive neural controller for the active control of earthquake-excited nonlinear base-isolated buildings," Struct Control Health, vol. 19, no. 3, pp. 370- 384, Apr. 2012.

[15] Y. Lei, D. T. Wu, and Y. Y. Lin, "A decentralized control algorithm for large-scale building structures," Comput-Aided Civ Inf, vol. 27, no.1, pp. 2-13, Jan. 2012.

[16] R. Mitchell, Y. Kim, T. El-Korchi, and Y. J. Cha, "Wavelet-neuro-fuzzy control of hybrid building-active tuned mass damper system under seismic excitations," J Vib Control, vol. 19, no.12, pp.1881-1894, 2013.

[17] A. Yanik, U. Aldemir, and M. Bakioglu, "A new active control performance index for vibration control of three-dimensional structures," Eng Struct, vol. 62-63, pp .53-64, March 2014

[18] B. Zhu, W. Lin,Q. Zhan, W. Sun, T. Hayat, and F. Alsaadi, “Active fault tolerant control of buildings for seismic loads in finite frequency domain," J Frankl Inst, vol. 352, no. 10, pp. 4247-4262, Oct 2015. 
[19] R. Mitchell, Y. J. Cha, Y. Kim, and A.A. Mahajan, "Active control of highway bridges subject to a variety of earthquake loads," Earthq Eng Eng Vib, vol. 14, no. 2, pp. 253-263, June 2015.

[20] N. Djedoui, O. Abdelhafid, and M. Abdeddaim, "Active vibration control for base-isolated structures using a PID controller against earthquakes," International Journal of Engineering Research in Africa, vol. 26, pp. 99-110, Oct. 2016.

[21] L. Xu, Y. Yunyan, and C. Yanliang, "Active vibration control for seismic excited building structures under actuator saturation, measurement stochastic noise and quantisation," Eng Struct, vol. 156, pp. 1-11, Feb 2018.

[22] L. Li, S. Gangbing, and O. Jinping, "Hybrid active mass damper (AMD) vibration suppression of nonlinear high-rise structure using fuzzy logic control algorithm under earthquake excitations," Struct Control Health, vol.18, no. 6, pp. 698-709, Oct. 2011.

[23] M. Soleymani, A. H. Abolmasoumi, H. Bahrami, S. A. Khalatbari, E. Khoshbin, and S. Sayahi, "Modified sliding mode control of a seismic active mass damper system considering model uncertainties and input time delay," J Vib Control, vol. 24, no. 6,pp.1051-1064, Mar. 2018.

[24] U. Aldemir, "Predictive suboptimal semiactive control of earthquake response," Struct Control Health, vol. 17, no. 6, pp. 654-674, Oct. 2010.

[25] M. Bitaraf, O. E. Ozbulut, S. Hurlebaus, and L. Barroso, "Application of semi-active control strategies for seismic protection of buildings with MR dampers," Eng Struct, vol. 32, no. 10, pp.3040-3047, Oct. 2010.

[26] M. Behnam and T. Khoshnoudian, "Performance-based semi-active control algorithm for protecting base isolated buildings from near-fault earthquakes," Earthq Eng Eng Vib, vol.11, no. 1, pp.43-55, Mar 2012.

[27] H. Ghaffarzadeh, E. A. Dehrod, and N. Talebian, "Semi-active fuzzy control for seismic response reduction of building frames using variable orifice dampers subjected to near-fault earthquakes," $J$ Vib Control, vol. 19, no. 13, pp. 1980-1998, 2013.

[28] N. M. Rahbari, B. Farahmand Azar, S. Talatahari, and H. Safari, "Semi-active direct control method for seismic alleviation of structures using MR dampers," Struct Control Health, vol. 20, no. 6, pp.1021-1042, June 2013.

[29] A. Yanik, J. P. Pinelli and H. Gutierrez, "Control of a three-dimensional structure with magneto-rheological dampers," in Proc. 11th International Conference on Vibration Problems. Lisbon, Portugal, 2013.

[30] S. M. A. Hashemi, H. Haji Kazemi, and A. Karamodin, "Localized genetically optimized wavelet neural network for semi-active control of buildings subjected to earthquake," Struct Control Health, vol. 23 , no. 8, pp.1074-1087, Aug. 2016.

[31] G. Yan, F. Chen, and Y. Wu, "A semi-active Ho control strategy with application to the vibration suppression of nonlinear high-rise building under earthquake excitations," SpringerPlus, vol.5, no. 1053, pp. 1-17, Dec. 2016.

[32] M. Braz-César and R. Barros, "Semi-active fuzzy based control system for vibration reduction of a sdof structure under seismic excitation," Smart Struct Syst, vol. 21, no. 4, pp. 389-95, 2018.

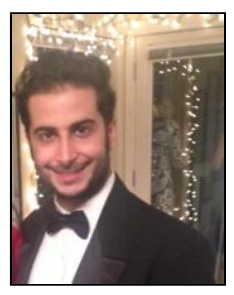

Arcan Yanik was born in Istanbul Turkey in 1983, he received his bachelor's degree in civil engineering from Yildiz Technical University (Istanbul Turkey) on 2006, he received his masters and $\mathrm{PhD}$ degrees from Istanbul Technical University (Istanbul-Turkey), Structural Engineering program on 2008 and 2014 respectively. He completed his postdoctoral studies at Oregon State University (Corvallis, OR USA), School of Civil and Construction Engineering, Structures Division on 2017. His major fields of study are vibration control, earthquake engineering and mechanics.

$\mathrm{He}$ works as an Asst. Prof. at the Istanbul Technical University, Department of Civil Engineering, Division of Mechanics. He worked as a Visiting Research Scholar at Florida Institute of Technology during the years of 2012-2013. The majority of his publications are about energy distributions in structures, structural control, structural dynamics, earthquake behavior of controlled structures, magneto-rheological dampers, and high-strength steels in reinforced concrete members. His research interests are Earthquake Engineering, Structural Control, Structural Dynamics, Mechanics, Numerical Analysis, Bridge Engineering and Magneto-Rheological Dampers.

Dr. Yanik is a member of Society for Experimental Mechanics and HKCBEES. He was awarded with the "Best PhD thesis award" given by Istanbul Technical University on 2015.

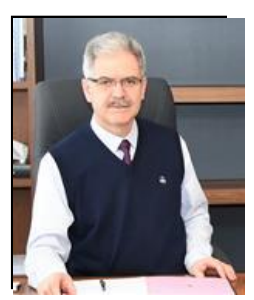

Unal Aldemir was born in Kirsehir Turkey in 1965 , he received his bachelor's degree in civil engineering from Bogazici University (Istanbul Turkey) on 1992, he received his masters and $\mathrm{PhD}$ degrees from Istanbul Technical University (Istanbul-Turkey), Structural Engineering program on 1994 and 1999 respectively. $\mathrm{He}$ completed his postdoctoral studies at Duke University Civil Engineering Department. He also visited Oregon State University as a visiting professor. His major field of study is mechanics, earthquake engineering and structural control.

He is the dean of the Faculty of Civil Engineering at the Istanbul Technical University. He works as a full professor and he is also the director of the Vibration Control and Research \& Development Lab of the Istanbul Technical University Civil Engineering Faculty. He has published more than 20 papers in reputed journals on the area of earthquake engineering, structural control and applied mechanics. His research interests include earthquake engineering, structural dynamics, optimal vibration control of structures under earthquake excitation, passive, active and semi-active systems in earthquake resistant structural design, base isolations, mass damper and seismic energy absorption devices and energy distribution of seismic energy in structures.

Prof. Aldemir has been awarded by several scholarships during his academic career from NATO, Duke University, Istanbul Technical University and Scientific and technological Research Council of Turkey (TUBITAK). 